\title{
LA SOLTERITA
}

Tonadilla que se cantoba en el Coliseo de México y que aún perdura

P O R

VICENTE T. MENDOZA

I A rutinaria existencia que se vivia en la Colonia de la Nueva España L durante los años anteriores a la Independencia era por demás monótona y aburrida. Los besamanos y santos de virreyes sólo eran accesibles a los vecinos ricos de la capital, el vulgo se conformaba con asistir a las procesiones del Corpus, a las ceremonias de Semana Santa o a los vitores en que se anunciaban las fiestas de los santos patrones de los barrios: San Agustín, la Merced, San Francisco, Santa María la Redonda o los Angeles. El Paseo del Pendón había caído en desuso, apenas si sobre endebles cabalgaduras aparecian el tamborilero y el clarinero de la ciudad que, en nombre del Ayuntamiento, recordaban el 13 de agosto de cada año la caída de Tenoxtitlán.

Apenas si la calma del país se conmovía con las inquietudes de los criollos, provocando motines con la "Sublevación de los machetes" que 
depuso audazmente al virrey Iturrigaray. Por lo demás, la vida se deslizaba muellemente y sin sobresaltos; los pacíficos habitantes de la noble ciudad, fuesen rancheros ricos, petimetres, jóvenes de la nobleza o funcionarios del Cabildo, asistían metódicamente al Coliseo los jueves y domingos para gustar de la representación de comedias como Luis XIV el Grande, La prudencia en la niñez o Reina loca de Hungria y divertirse en los entreactos con follas, miscelánea, con tonadillas como " $L$ a varita de virtud" o con sonecillos del país que empezaban a irrumpir en medio de los géneros españoles.

Por aquel entonces privaban en las tablas los famosos tonadilleros Lola Carpintero, Lola Munguía "La Chata", Luciano Cortés, Miguel Maya, Francisco Saldaña y Victorio Rocamora; pero, sobre todo, la famosa "Inesilla", Inés García, quien en 1808 puso de moda, por su gracia y desparpajo, algunas tonadillas imitadas de las españolas, entre las que se hallaban "La solterita", "La salerosa", "Yo soy, señor, una mocita" o "La desapasionada", y fué esta misma tonadillera quien gradualmente $y$ sin sentir imptso los sones de la tierra, tales como "El jarabe" y "La bamba poblana".

Años más tarde, cuando las luchas por la Independencia de México exaltaron las pasiones $y$ despertaron la inquina de los bandos, esta misma Inés García, en la temporada de 1813 y en su función de beneficio, hizo prodigios y dió muestra de su talento ante el mismo virrey Calleja. Debe haber sido admirador de las bellezas teatrales el mencionado virrey, puesto que en dicha ocasión, al presentarse en el proscenio la simpática tonadiJlera, hizo que sus ayudantes arrojasen a sus pies más de cien onzas de oro y, según cuenta la Gaceta de la época, no sólo otras muchas personas lanzaron al escenario monedas $y$ alhajas, "hilos de perlas, aretes, cruces $y$ aderezos completos de brillantes, cofrecitos de oro, rosarios y relojes con piedras finas", sino que la misma virreina le envió uno de sus mejores aderezos de brillantes.

Motivo de este artículo es la mencionada tonadilla de "La solterita", indudablemente compuesta en México por autor anónimo, pero que menciona curiosamente, en su texto, los diversos conventos de monjas existentes en esta capital y algunos pormenores de su vida interior, durante la primera década del siglo xix. Don Enrique de Olavarría y Ferrari. en su Reseña histórica del Teatro en México, tuvo la suerte de encontrar, en los diversos archivos que removiera para escribir su interesante obra. el texto completo, el cual reproduzco en este lugar: 


\section{LA SOLTERITA}

\section{Tonadilla}

Para quitarme del mundo y su quimera, viéndome pobre, soltera $\checkmark$ abandonada; hallándome atribulade me fuí a un jardin a pensar cuál sería el fin de mis amores:

Hallándome entre las flores más especiales, para alivio de mis males quise pensar. un destino que tomar para mi estado:

Si me meto con soldado me causa tedio. pues una mujer con medio no ha de hacer nada: yo no quiero ser casada por mis hijitos cuando tengan hambre a gritos me aturdirán: sin ni frijoles ni pan, $y$ esto me amobina: si me meto a capuchina, soy dormilona; para ayunar soy tragona $y$ es impaciencia: no quiero hacer penitencia, que es tiranía: si voy a Jesús María: pelan las cocas 1 y querrán que baga las sopas pa'la función:

si voy a la Encarnación por mi desdicha. querrán que haga yo la chicha ${ }^{2}$ $y$ que esté fina;

si me meto a Catalina por mia conflictos, querrán que haga rosarito: $y$ de San Blas; en la Enseñanza no más es gritería, querrán sea a toda porfía maestra de amiga; 8 no estoy para bacer fatiga por ningún pienso. si me theto a San Lorenzo como pudiera, querrán que sea alfeñiquera en conclusión; si voy a la Concepción, arman mil bullas, querrán que cante aleluyas todito el dia; en Santa Clata a porfía. como son pocas, querrín que haga yo las tocas para las muertas;

en Santa Isabel, son tuertas las mandaderas $y$ tendré mil molederas pues no van bien: en las Brígidas, también recolección ${ }^{5}$ y querrán que a la oración ya esté durmiendo: monja de San Juan, no entiendo ser franciscana, andat vestida de lana $y$ amortajada;

1 Se refiere a la cabeza rapada como coco.

2 En México consumía entonces chicha hecha de frutas.

3 Colegio de párvulos en que se enseñaba el silabario y la doctrina.

4 Las eriadas de este convento eran disimuladas.

5 Propiamente de monjas recoletas. 
en Regina no habrá nada,

ni quien me asista,

querrán que yo sea organista.

y a la verdad,

al jay! de mi falsedad

estaré enszyando:

todo me estará amohinạdo,

pues no lo entiendo:

si Jerónima pretendo,

como pudiera.

buena calabacetera

saldré de allí:

las Bernardas para ani

son cocoritas,

querrín que baga toataditas

pa'los purgados,

gastaté dos mil enfados

por mi falacia;

monja en San José de Gracia

es gran tontera,

querrán que sea campanera

cuando novicia,

y seri grande injusticia

hacerlo adi :

Balvaera para mí

es buen convento;

peto tampoco consiento

porque son finas.

hacen flores cartalinas

sin interés;

si me meto a Santa Inés

alli se observa

estar baciendo conserva

que es buena pieza:

yo no quiero ser Teresa:

pues me hará mal,

comer comida sin ol y mondas habas;

en las Mochas ${ }^{B}$ paño $y$ naguas

he de tenet,

¿quién me querrá mantener

alli metida?

Pues me ballo tan desvalida

del valimiento;

si yo a las $N$ iñas consiento

entrar, me muero:

pues querrán que el diz primero

pague mi piso:

¿quién me hacá este beneficio?

No tengo quien:

en las Vizcaínat también

son gachupinas

y como aquellas son finas

y yo soy criolla $T$

con mi tompeatito $y \mathrm{mi}$ olla

vendré a parar.

sin poderlo remediar,

de limosnera;

no he de sex recamarera

ni ama de llave.

quiero un trabajito suave

de sentadita,

y a cualquiera fiestecita

que se me ofrezca

salir a pasear bien puesta,

bien regalada,

bien comida y bien paseada,

todo to admito:

en ia noche a un fandanguito

me llevarán,

ya sea Pedro, ya sea Juan,

nada me importa,

el fin es buscar la torta

y nada más.

Como se ve por el texto anterior, el metro deriva del de la seguidilla, con la circunstancia de ser el primer verso octosílabo, es decir, que la seguidilla ha sido modificada en México, haciendo crecer en una sílaba el verso heptasílabo. A la forma de rimar el verso corto con el largo siguiente

6 Antiguo Colegio de Belén de las Mochas.

7 Declara Inés Garciz no ser española, sino hija del país. 
podría llamársele pareada si fuese al revés, es decir, el primero con el segundo y el tercero con el cuarto, etc.; pero tal como aparece viene a resultar una cadena de pie quebrado.

No habiéndose encontrado hasta hoy ninguna fuente de información acerca de la música con que se cantaban las diversas tonadillas que se ejecutaron en el Coliseo de México, ni se ha dado a la estampa ninguna obra, que yo sepa, que trate este asunto siquiera sea someramente, que pudiera orientarnos hacia donde existe dicha música, he recurrido a textos folklóricos recogidos por mí en diversos lugares y ocasiones y puedo presentar en este caso dos melodias que juzgo sean pervivencias melódicas de la mencionada tonadilla y nos demuestran cómo se ha conservado la música, aunque los textos han variado, a través de 137 años, asi como la boga que alcanzó y la amplitud geográfica de difusión que logró en ese lapso. El primero de estos documentos me fué proporçionado por la señora Graciela Arriador y procede de Zacatecas; es sólo un fragmento y su aspecto nos habla elocuentemente de su antigüedad, pues la comunicante nos informó ser ya conocido entre su familia hace lo menos cincuenta años.

\section{EL MAL CASADO}
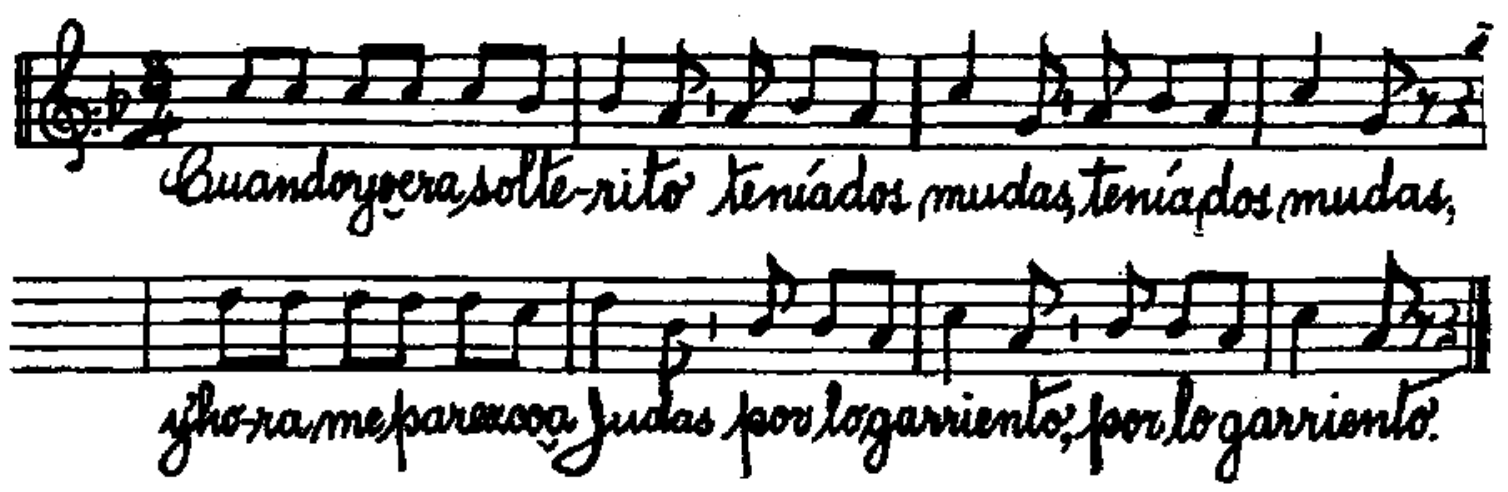

Cuando yo era solterito tenía dos mudas (bis) y abora me parezco a Judas ea 10 hilachento. (bis) Como gato de convento por los rincones (bis) remendando mis calzones con pita floja. (bis) $Y$ es lo que mís me acongoja
I el set caeado, (bis) la mula que me ha tocado que ya reniego. (bis) Si a la cocina me allego pido tortilla (bis) se suelta la tarabilla de mi cuñada. (bis) |Ayy qué gata malhadadal... 
El segundo ejemplo, que se canta con la misma melodía del anterior, procede de Sinaloa y fué comunicado por el señor José de Garay; su texto es muy semejante al de $E l$ mal casado, pero tiene modificaciones substanciales en la forma, pues no conserva ésta rigurosamente como cadena de pie quebrado.

\section{EL SOLDADITO}

Cuando estaba yo en mi casa de paisanito. andaba muy arreglado y aliñadito, con $\mathrm{mi}$ cotón colorado muy bien planchado.

Tenía dos mudad y ahora me parezco a Judas en lo bilachento.

Como gato de convento arrinconado. remendando mis calzones

con pita floja.

$Y$ esto es lo que me acongoja

$y$ en este estado

tan desgraciado.

Son las cinco'e la mañana

$y$ mi sargento

me manda que hage la guardia, yo le contesto.

-No sea respondón y malo. porque lo friego, dc un palo.

El tercer ejemplo es más nutrido, literariamente mejor conservado; tiene diversa melodia y es una adaptación cuyo principio y fin rompen las condiciones de la cadena de pie quebrado, conservándolas, sin embargo, en la mayor parte del cuerpo. Fué recogida por mi en Los Reyes, Mich, en octubre de 1926, de labios de la señorita Ana María Ochoa:

\section{LAS MUCHACHAS}

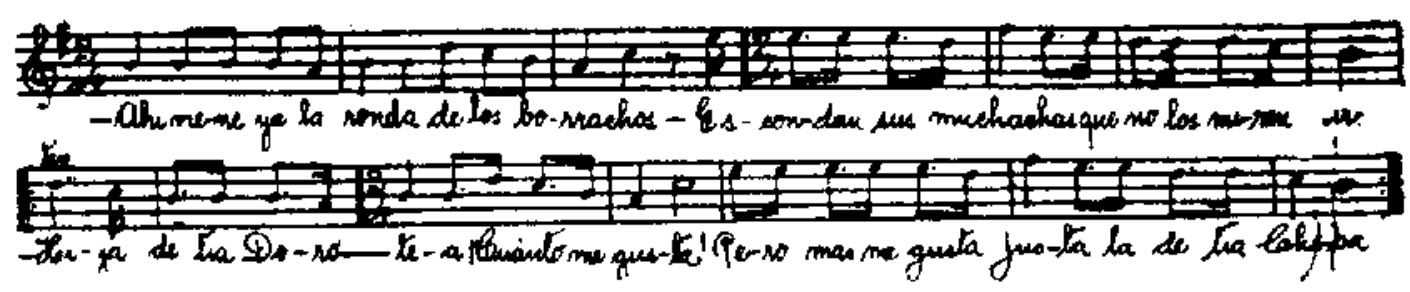

Ahí viene ya la ronda de los borrachos, escondan sus muchachas, que nos los miran ir. --Hija de tia Dorotea, jcúnto me gustal
Pero más me gusta Justa, la de tía Chepa.

-Lástima que no me quepa duda de Blasa.

-Yo prefieto a Nicolasa con Jesusita. 
-Esta duda no la quito ni tía Mercedes.

- Solamente que te quedea en la Parota.

-A mi me gusta Carlota con sus humores.

-Yo preferiría a Dolores

- a Celestina.

- Si se me pandea la esquina prefiero a Lupe.

-Sólo que ya no la ocupe don Pantaleón.

-Si viniera Concepción

con su linda trenza...

-Yo sólo con mi Lorenza

voy de paseo.

-No te quedes con deseo, llévate a Carmen.
Sna bermanos que te la armen con tus pendencias.

-Entre ellas viene Clemencia

b de tía Paca.

-Esa ya nadie la aplaca

ni con espuelas.

- Luisa viene con Estela

$y$ con Catalina.

- Ya se me clavó la espina

con sus amores.

$\rightarrow$ il a coronatias de flores

en el huizache?

-Estrenando mi huarache

Dios me acompañe.

La prefiero con sus cuñas

aunque me engañe.

que se recorte las uñas

para que a mi no me arañe.

Este texto que aparece en forma alternativa, un tanto atropellada, en que los borrachos en pandilla van dando sus opiniones sobre las muchachas de la población en forma tan desenfadada, deriva directamente de aquellos romances del siglo pasado, a que tan aficionados fueron nuestros abuelos, hechos con nombres de mujeres o de hombres; viene a ser la prolongación directa de la tonadilla de "La solterita", que hemos venido estudiando, cuya identificación se hacía necesaria y he logrado, hasta donde ha sido posible, con los ejemplos anteriores. $Y$ para concluir agregaré un texto, aunque sin música, que comunicó la señorita Trinidad Espinosa, de Chavinda, Mich., que viene a ser la contraparte del texto literario que acompaña la tonadilla de "La solterita".

\section{VERSOS DEL CONVENENCIERO}

Yo de galán de a pie

no me acomodo,

voy a buscar otro modo

de hacer petates.

- me voy a los Orates.

- 2 las Jarrillas.

y si no a las Matavillas

a bacer coronas.

Mejor me voy a las Lomas

a seguir liebres: 


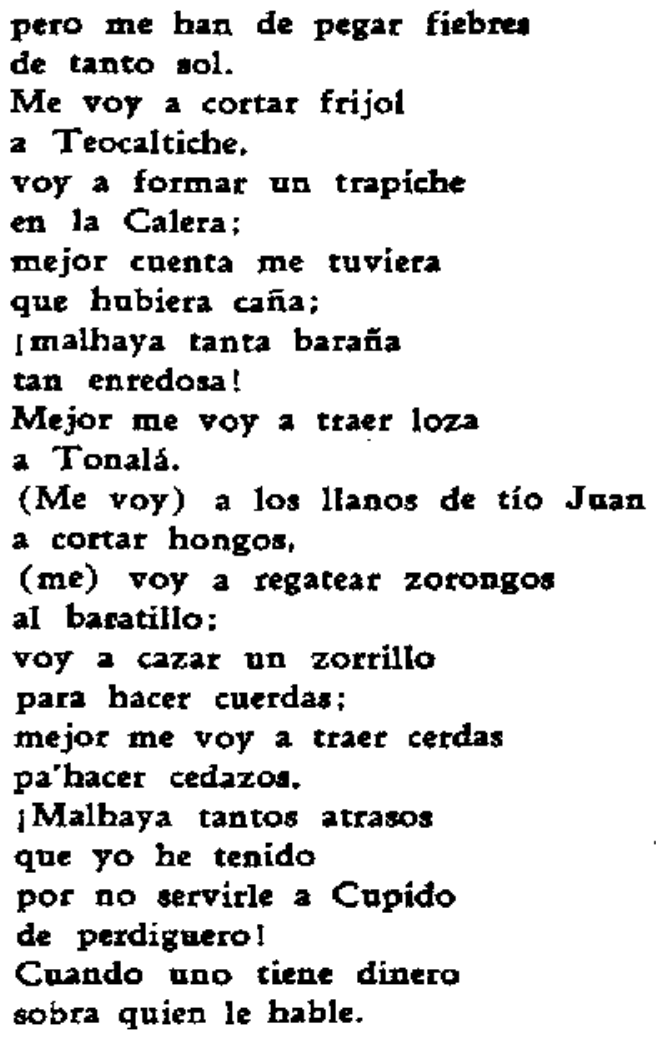

